\title{
The size of the foramen ovale regarding to the presence and absence of the emissary sphenoidal foramen: is there any relationship between them?
}

\author{
K. Natsis ${ }^{1}$, M. Piagkou² , E. Repousi² ${ }^{2}$ T. Tegos ${ }^{3}$, A. Gkioka², M. Loukas ${ }^{4,5}$ \\ ${ }^{1}$ Department of Anatomy, Faculty of Health and Sciences, Medical School, Aristotle University of Thessaloniki, Greece \\ 2Department of Anatomy, Medical School, National and Kapodistrian University of Athens, Greece \\ ${ }^{3}$ Department of Neurology, AHEPA Hospital, Aristotle University of Thessaloniki, Greece \\ ${ }^{4}$ Department of Anatomical Sciences, School of Medicine, St. George's University, Grenada, West Indies \\ ${ }^{5}$ Department of Anatomy, Varmia and Mazuria University, Olsztyn, Poland
}

[Received: 14 November 2016; Accepted: 23 May 2017]

Background: The study investigates the size of the foramen ovale (FO) in relation to the presence and absence of the emissary sphenoidal foramen (ESF). Any possible alteration of the FO size in relation to the ESF (unilateral or bilateral) presence and absence was also examined.

Materials and methods: One-hundred and ninety-five (117 male and 78 female) Greek adult dry skulls were investigated.

Results: The ESF was present in $40 \%$ of the skulls $21.5 \%$ bilaterally and $18.5 \%$ unilaterally). No statistical significant difference was detected between ESF presence or absence and its unilateral or bilateral occurrence. The ESF existence had no relation to the $F O$ size.

Conclusions: The ESF absence or presence has no effect on FO size. The emissary sphenoidal vein is an additional venous pathway connecting cavernous sinus with the pterygoid venous plexus. These findings enhance that the venous plexus of the FO is a constant trait. The meticulous knowledge of the middle cranial fossa anatomy is of paramount importance during transovale procedures, as the outcome of cannulation may be affected by the existence of ESF, the confluence FO-ESF, the existence of osseous spurs and bridging into the FO. (Folia Morphol 2018; 77, 1: 90-98)

Key words: emissary vein, foramen ovale, foramen Vesalius, middle cranial fossa

\section{INTRODUCTION}

Foramen ovale (FO) is the most important constant foramen of the greater sphenoidal wing in the middle cranial fossa. A single reference exists about its atypical position on the lateral side of the pterygoid process medially to the infratemporal fossa [35]. Although the content of the FO may vary, the included mandibular nerve and a venous plexus (connecting cavernous sinus with the pterygoid venous plexus) encircling the nerve are always present $[16,19,41]$.

Address for correspondence: M. Piagkou, Assistant Professor, DDS, MD, PhD, MSc, Department of Anatomy, School of Medicine, Faculty of Health Sciences, National and Kapodistrian University of Athens, Greece, tel: +30 210 6924507, fax: +30 210 7462398, mob: +306984316353, 

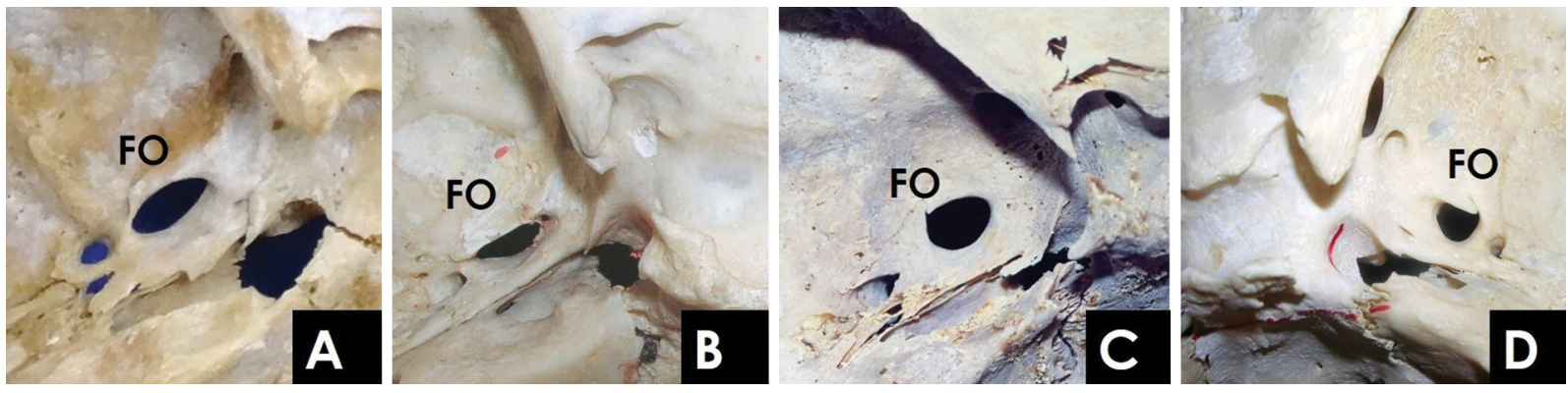

Figure 1. Types of foramen ovale (FO) shape; A. Oval type; B. Almond-type; C. Round-type; D. Irregular-type.

Anteromedial and in close proximity to the FO, the small inconstant emissary sphenoidal foramen (ESF), largely known as foramen Vesalius (or foramen venosum) is located and it always transmits an emissary vein, also connecting pterygoid venous plexus with the cavernous sinus $[13,20,39]$. It is a reasonable assumption that any change of the volume and shape of the venous plexus may alter FO shape and size. Searching the literature, variability exists as regards the FO types of shape (oval, truly oval, elongated oval, elongated, semicircular, almond, round, rounded, slit, irregular, D shape and pear) $[7,23,37]$ and FO size (length and width) among studies. As regards FO length, the higher values were recorded by Patil et al. [27] and Murugan and Saheb [22], while lower values were found by Kaplan et al. [16], Natsis et al. [23], Lang et al. [17] and Agarwal and Gupta [1]. As regards FO width, the highest values were reported by Lin et al. [20] and Yanagi [43] and the lowest values were detected by Ray et al. [29]. Wood-Jones [42] supported that in cases of ESF existence, the FO venous part may be replaced by the sphenoidal emissary vein. A relationship was detected between FO and ESF, as in unilateral ESF occurrence, the ipsilateral FO was smaller compared to the contralateral FO [42]. Moreover, Henderson [14] following the dissection of 100 cadavers, observed that when the ESF was present, the FO venous part was absent.

Following the years, several anatomical studies have focused on FO morphology and morphometry and the ESF presence, absence, morphology and morphometry $[9,12,21,25,30,33]$, but only the study of Wood-Jones [42] was referred to the correlation of FO morphology and the ESF presence or absence. Considering the above observations, we decided to investigate $\mathrm{FO}$ size in relation to the ESF absence or presence. Firstly, we examined the morphometric details of the foramina Vesalius and ovale and the distances between them according to the side of occurrence, the gender and the age. Then, we investigated any possible alteration of the FO size in relation to the absence or presence (unilateral, right and left side or bilateral) of the ESF.

\section{MATERIALS AND METHODS}

One-hundred and ninety-five (117 male and 78 female) intact adult dry skulls were collected from our departments. The skulls derived from Greek cadavers donated to our laboratories between 1990 and 2015, were further divided into three age-groups: 20-39 years of age (32 skulls), 40-59 (52 skulls) and 60 and above (111 skulls). Skulls damaged in the floor of the middle cranial fossa and skulls with gross evident deformities were excluded. The FO morphometry was investigated in all skulls in the infratemporal fossa. FO shape was classified into oval, almond, round and irregular types (Fig. 1). The whole sample was examined for a patent ESF by using an orthodontic wire (thickness $0.2 \mathrm{~mm}$ ) and the morphometry of the patent foramina was studied. All skulls were placed vertically to the horizontal plane on a stand with the external occipital protuberance located to the horizontal plane. They were photographed with a Sony 16.1-megapixel Digital Camera (fixation $47.5 \mathrm{~cm}$ away from the ESF). A digital image processing software (Image $J$ ) was used for the measurements of the FO and ESF anteroposterior length and transverse width. The minimum distance from the inferior border of the ESF to the superior border of the FO was also measured (Fig. 2). All measurements were performed by a single investigator and they were taken twice and average of the two values was taken as final measurement. The FO was examined for the existence of bony spurs (Fig. 3) for its confluence with ESF (Fig. 4) and both FO and ESF were investigated for duplication/multiplication (Fig. 5) or any other additional 


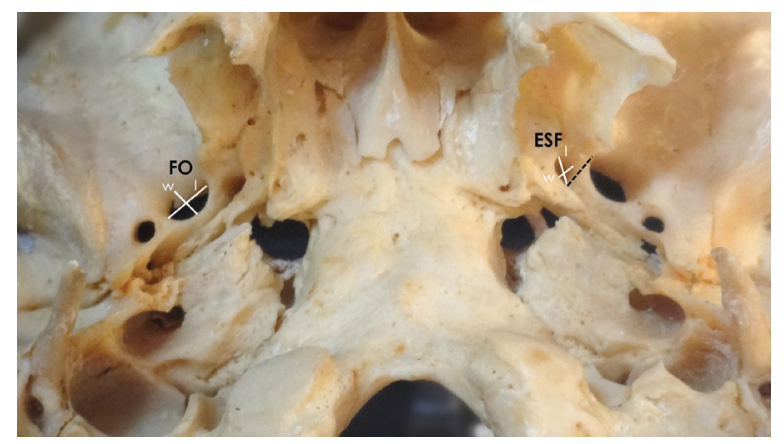

Figure 2. Foramen ovale (FO) and emissary sphenoidal foramen (ESF) anteroposterior length (I) and transverse width (w) and the dotted black line representing the distance FO-ESF.

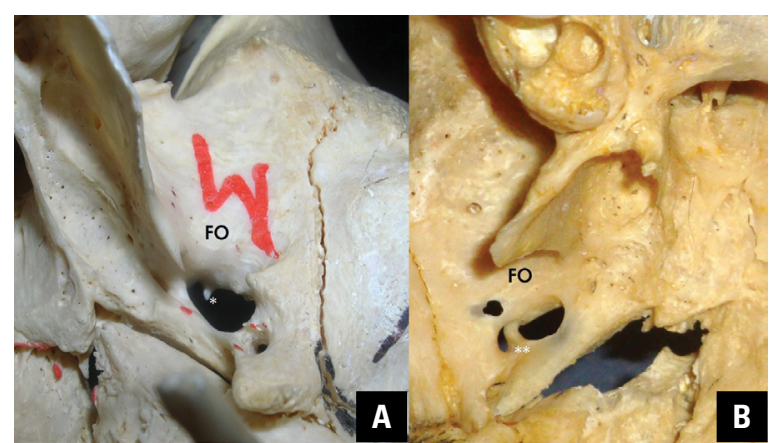

Figure 3. Foramen ovale (FO) spur $\left({ }^{*}\right)(\mathbf{A})$ and osseous bridging $\left(^{* *}\right)(\mathbf{B})$.

foramina. We studied FO dimensions separately in skulls without ESF, in skulls with bilateral present
ESF and in skulls with unilateral present ESF, in order to detect any possible alteration on the FO dimensions related to the ESF absence or presence. Thus, our sample was subdivided into 117 skulls without ESF, into 42 skulls with bilateral present ESF, into 14 skulls with a right-sided ESF and into 22 skulls with a left-sided ESF. The skulls without ESF were used as a control group and the measured FO dimensions were used as a standard for evaluation of any further correlation.

\section{Statistical analysis}

Descriptive statistics (mean \pm standard deviation, median, minimum and maximum values) were evaluated for all the measured parameters. The Kolmogorov-Smirnov test was performed for the evaluation of normality of the distributions. Non parametric $\chi^{2}$ test was used to detect differences between percentages. The paired sample T-test was used to investigate side asymmetry and the independent sample test for gender dimorphism. The one-way ANOVA was performed for the correlation of the above parameters with the age. The independent sample T-test was used to detect any difference between the measured parameters. Pearson correlation test was used for the correlation between the measured parameters. For all the analyses, $p$ values $<0.05$ were accepted as statistically significant, and statistical analysis was carried out using IBM SPSS Statistics for Windows, version 21.0.
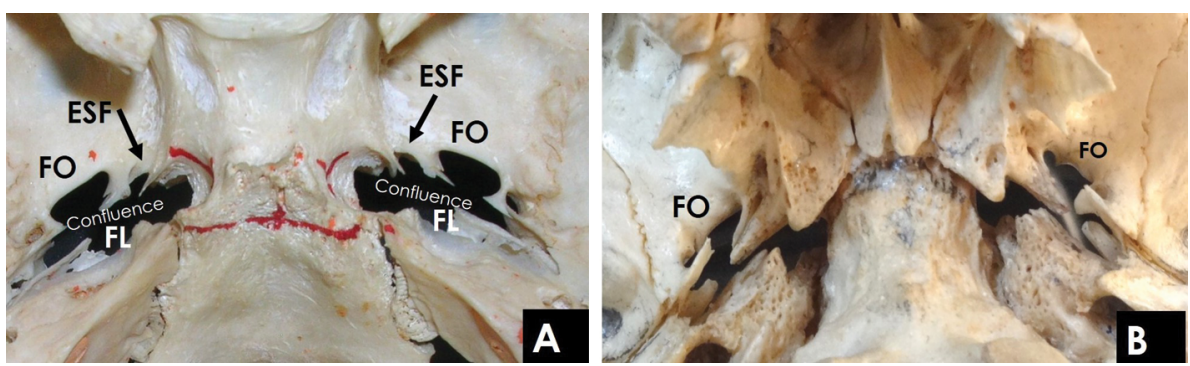

Figure 4. A. Foramen ovale (FO) and emissary sphenoidal foramina (ESF) (black arrows) confluence into foramen lacerum (FL); B. F0 confluence into ESF.

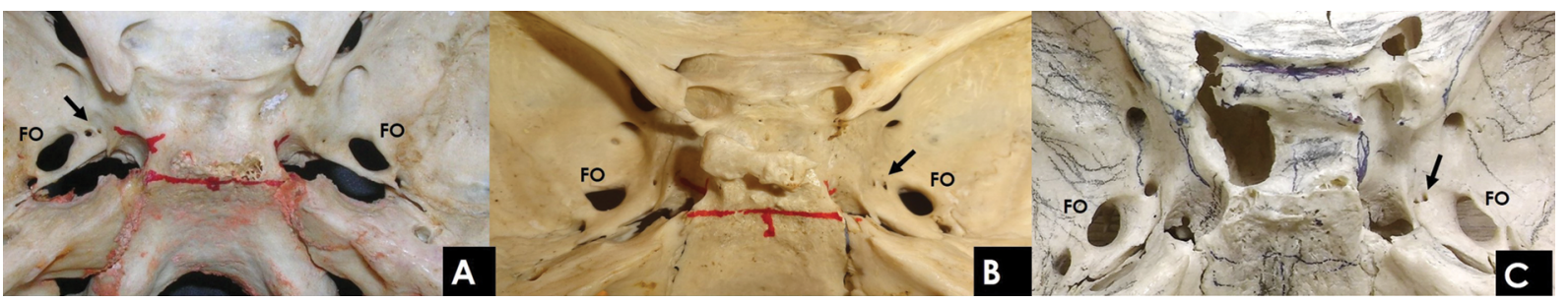

Figure 5. Emissary sphenoidal foramen duplication (black arrow) on the left side $(\mathbf{A})$ and on the right side $(\mathbf{B}, \mathbf{C})$ of the skull and a single emissary sphenoidal foramen to the contralateral side of the skull (A, B); FO — foramen ovale. 


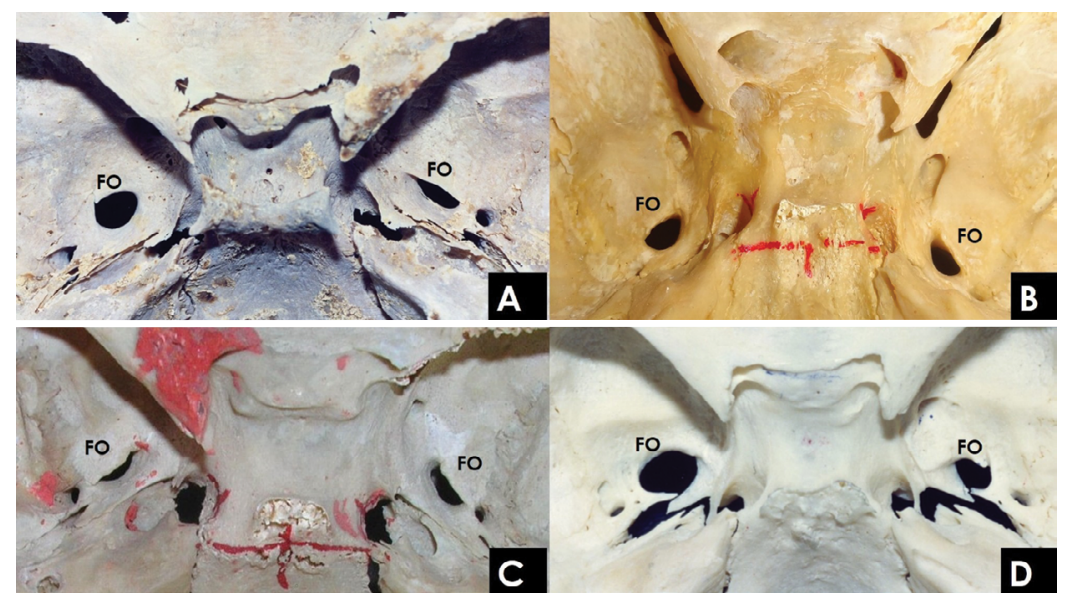

Figure 6. Absence of the emissary sphenoidal foramina with asymmetry in the foramen ovale (F0) shape (A) location (B) and size (C, D).

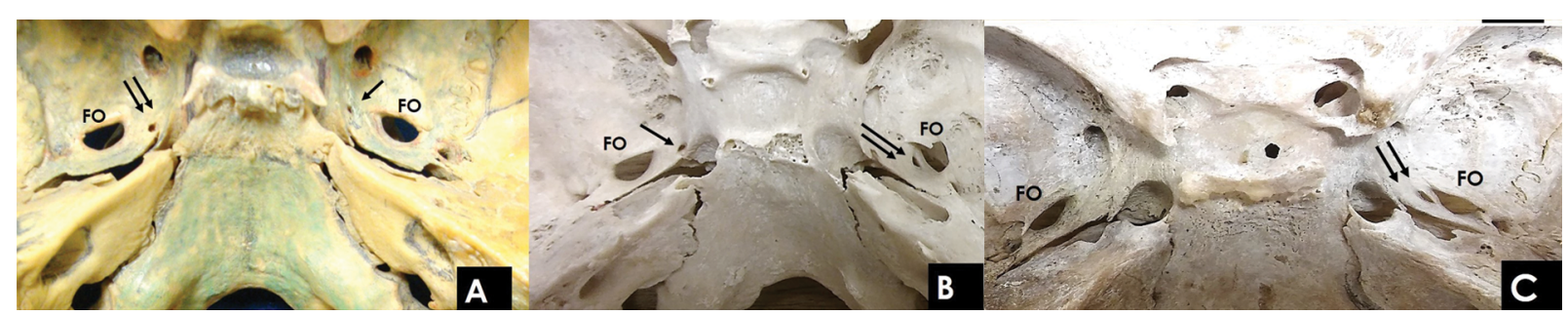

Figure 7. A, B, C. Location of the emissary sphenoidal foramina anteromedial (single black arrows) and medial (double black arrows) to foramina ovalia (FO).

\section{RESULTS}

Foramen ovale was detected in all skulls and it was typically oval in $56.1 \%$ (49.6\% on the right and $62.6 \%$ on the left side), almond in $19.1 \%$ ( $23.5 \%$ on the right and $14.8 \%$ on the left), irregular in $16.5 \%$ (19.1\% on the right and $13.9 \%$ on the left side) and round in $8.3 \%$ ( $7.8 \%$ on the right and $8.7 \%$ on the left). No correlation was detected between FO shape, the gender and the age. The FO morphometric details presented a normal distribution ( $p>0.05$, Kolmogorov-Smirnov test). In the entire sample, the mean value of the FO length was $7.63 \pm 1.17 \mathrm{~mm}$ on the right and $7.48 \pm$ $\pm 1.20 \mathrm{~mm}$ on the left side. The mean value of the FO width was $4.47 \pm 1.00 \mathrm{~mm}$ on the right and $4.59 \pm$ $\pm 1.00 \mathrm{~mm}$ on the left side. No statistical significant difference was detected in $\mathrm{FO}$ dimensions regarding to the side of occurrence (FO lengths right and left, $\mathrm{p}=0.218$ and FO widths right and left, $\mathrm{p}=0.492$ ). The average values of the FO lengths right and left in males were 7.75 and $7.73 \mathrm{~mm}$ and in females were 7.73 and $7.29 \mathrm{~mm}$, respectively $(p=0.938$ and $p=0.152$ ). The average values of the FO widths right and left in males were 4.32 and $4.65 \mathrm{~mm}$ and in females were 4.42 and $4.38 \mathrm{~mm}(\mathrm{p}=0.706$ and $p=0.308$ ). No gender dimorphism was observed regarding to the FO morphometry. Moreover, no statistical significant difference was detected between FO length right and left side with the age, $p=0.117$ and $p=0.367$ and FO width right and left side with the age, $p=0.310$ and $p=0.259$.

The ESF was present in $78(40 \%)$ skulls and absent in $117(60 \%)$ skulls. It was detected in $42(21.5 \%)$ skulls bilaterally and in $36(18.5 \%)$ skulls unilaterally (14 right; $7 \%$ and 22 left; $11 \%$ ) (Figs. 6-8). No statistical significant difference was found between ESF presence or absence $(p=0.163)$ and its unilateral or bilateral occurrence $(p=0.182)$. All morphometric characteristics of the ESF presented a normal distribution ( $p>0.2$, Kolmogorov-Smirnov test). In all skulls with ESF, the mean values of the ESF length and width were $2.70 \pm 0.60 \mathrm{~mm}$ and $1.76 \pm 0.53 \mathrm{~mm}$. The right and left-sided ESF lengths were $2.63 \pm 0.9 \mathrm{~mm}$ and $2.79 \pm 0.65 \mathrm{~mm}$. The right and left-sided ESF widths were $1.70 \pm 0.48 \mathrm{~mm}$ and $1.83 \pm 0.59 \mathrm{~mm}$ (Table 1). No side asymmetry was detected as regards to the ESF lengths $(p=0.661)$ and widths $(p=0.945)$. The mean 


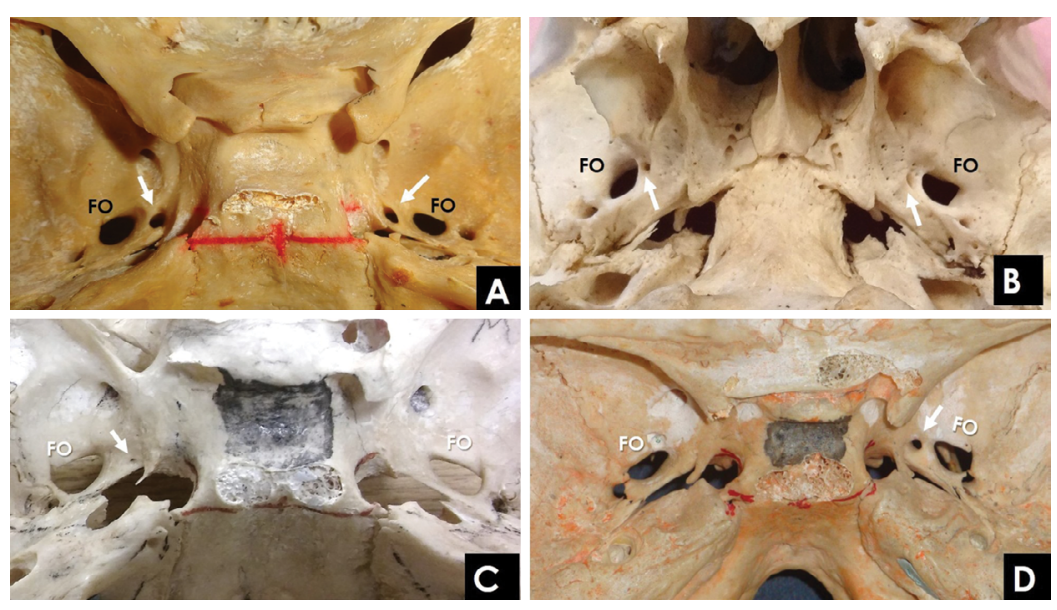

Figure 8. Emissary sphenoidal foramina presence (white arrows) bilaterally (intracranially — A and exocranially — B). Unilateral presence (white arrows) of emissary sphenoidal foramina (left sided — C and right sided - D); F0 — foramen ovale.

Table 1. The emissary sphenoidal foramen (ESF) dimensions (length and width) on the right and left side in skulls

\begin{tabular}{|c|c|c|c|c|c|c|c|}
\hline \multirow[t]{2}{*}{ ESF dimensions } & \multicolumn{2}{|c|}{ Mean \pm standard deviation } & \multicolumn{2}{|c|}{ Minimum } & \multicolumn{2}{|c|}{ Maximum } & \multirow[t]{2}{*}{$\mathbf{p}$} \\
\hline & Right side & Left side & Right & Left & Right & Left & \\
\hline Length & $2.63 \pm 0.9$ & $2.79 \pm 0.65$ & 0.74 & 1.44 & 4.35 & 3.80 & 0.2 \\
\hline Width & $1.70 \pm 0.48$ & $1.83 \pm 0.59$ & 0.41 & 0.40 & 2.51 & 2.83 & 0.2 \\
\hline
\end{tabular}

right and left-sided ESF lengths in males were 2.73 and $2.83 \mathrm{~mm}$ and in females were 2.76 and $2.75 \mathrm{~mm}$. The average right and left-sided ESF widths in males were 1.71 and $1.82 \mathrm{~mm}$ and in females were 1.68 and $1.84 \mathrm{~mm}$. No gender dimorphism (ESF right-sided length, $p=0.577$, left-sided, $p=0.760$, ESF right-sided width, $p=0.706$ and left-sided, $p=0.308$ ) and no statistical significant difference was found between ESF dimensions and the age grouping (ESF right-sided length, $p=0.772$, left-sided, $p=0.686$, ESF right-sided width, $p=0.557$ and left-sided, $p=$ $=0.647$ ). The mean \pm standard deviation, the minimum and maximum values of the FO-ESF distance were $2.40 \pm 0.9 \mathrm{~mm}, 0.9 \mathrm{~mm}$ and $5.29 \mathrm{~mm}$ on the right side and $2.22 \pm 0.79 \mathrm{~mm}, 0.97 \mathrm{~mm}$ and 4.20 $\mathrm{mm}$ on the left side. No statistically significant difference was found between FO-ESF distance and the side of occurrence $(p=0.068)$, the gender $(p=0.390$ right and $p=0.147$ left) and the age grouping ( $p=$ 0.599 right and $p=0.908$ left).

A double ESF was found in 2 skulls (in one skull on the right and in the other on the left side). A confluence between FO and ESF was detected in 2 skulls (in a skull bilaterally and in the other on the right side). Osseous spurs were also observed into the cranial opening of the FO in 2 skulls on the right side. No additional foramina were observed.

The FO dimensions in skulls without ESF, in skulls with bilateral and unilateral ESF are summarised in Table 2. We compared the values of the FO dimensions between the skulls with bilateral, right and left sided ESF to the skulls without ESF (control group) and no statistical significant difference was found $(p>0.1)$. Moreover, we examined the side differences of the FO dimensions (length and width) in the above groups and a side symmetry was detected ( $p$ $>0.1$ ). In Pearson correlation analysis, we examined FO length and width with the ESF length and width on both sides (length to length - width to width correlation) and also the distance FO-ESF with the FO and ESF dimensions. A positive correlation was found between the distance FO-ESF and the ESF length and width on both sides (Table 3). All the other correlations were not statistically significant.

\section{DISCUSSION}

The emissary veins, connecting the intracranial venous sinuses with the exocranial veins, may pass through various skull apertures, either constant or inconstant emissary foramina. In particular, emissary 
Table 2. The foramen ovale (FO) dimensions on the right and left side in skulls without and with emissary sphenoidal foramen (ESF) (bilateral and unilateral — on the right and left side) of the ESF

\begin{tabular}{|c|c|c|c|c|c|c|}
\hline \multirow[t]{2}{*}{ ESF } & \multicolumn{2}{|c|}{ Mean \pm standard deviation } & \multicolumn{2}{|c|}{ Minimum } & \multicolumn{2}{|c|}{ Maximum } \\
\hline & Right side & Left side & Right & Left & Right & Left \\
\hline \multicolumn{7}{|l|}{ FO length } \\
\hline Without ESF & $7.60 \pm 1.3$ & $7.38 \pm 1.13$ & 5.12 & 4.71 & 10.40 & 10.20 \\
\hline Bilateral presented & $7.72 \pm 1.10$ & $7.44 \pm 1.45$ & 5.91 & 5.42 & 10.36 & 11.17 \\
\hline Right-sided & $7.96 \pm 1.28$ & $8.23 \pm 1.44$ & 5.93 & 6.36 & 10.23 & 12.08 \\
\hline Left-sided & $7.31 \pm 1.01$ & $7.28 \pm 1.1$ & 5.31 & 8.06 & 9.05 & 9.46 \\
\hline \multicolumn{7}{|l|}{ F0 width } \\
\hline Without ESF & $4.27 \pm 1.01$ & $4.33 \pm 0.89$ & 2.50 & 2.66 & 6.45 & 6.56 \\
\hline Bilateral presented & $4.43 \pm 0.96$ & $4.64 \pm 1.14$ & 2.23 & 2.68 & 6.87 & 7.57 \\
\hline Right-sided & $4.68 \pm 0.85$ & $4.75 \pm 1.04$ & 2.96 & 2.80 & 6.20 & 6.95 \\
\hline Left-sided & $4.76 \pm 1.15$ & $4.85 \pm 0.86$ & 2.37 & 3.44 & 6.64 & 6.85 \\
\hline
\end{tabular}

Table 3. Pearson correlation analysis between the measurements

\begin{tabular}{lccccc}
\hline Correlations & \multicolumn{2}{c}{ Right side } & & \multicolumn{2}{c}{ Left side } \\
\cline { 2 - 3 } \cline { 5 - 6 } & $\mathbf{p}$ & $\mathbf{r}$ & $\mathbf{p}$ & 0.225 \\
\hline FO length with ESF length & 0.786 & -0.061 & 0.302 & 0.364 \\
FO width with ESF width & 0.083 & -0.378 & 0.06 & 0.502 \\
FO-ESF with ESF length & 0.048 & 0.468 & 0.04 & 0.537 \\
FO-ESF with ESF width & 0.014 & 0.553 & 0.032 & 0.007 \\
FO-ESF with FO length & 0.875 & -0.022 & 0.958 & 0.093 \\
FO-ESF with FO width & 0.08 & 0.249 & 0.507 & \\
\hline
\end{tabular}

FO — foramen ovale; ESF — emissary sphenoidal foramen

veins draining the cavernous sinus to the pterygoid venous plexus may pass through the foramen rotundum, the ESF, the FO, the foramina spinosum and lacerum. The emissary veins of the foramina rotundum and ovale form a venous plexus surrounding the enclosed nerves $[16,19,41]$. The FO venous plexus is the main pathway of the cavernous sinus drainage to the pterygoid venous plexus [19] and it is the main factor influencing the FO size [31]. Williams et al. [41] in their study regarding the trigeminal nerve and the perineural vascular plexus found that the dimensions of the venous plexus surrounding the mandibular nerve were larger compared to the dimensions of the venous plexus compassing the maxillary nerve. Liang et al. [19] in their study about the transcranial segment of the trigeminal nerve observed that the FO size was larger than the size of the included mandibular nerve and the rest part of the cranial opening was occupied by the periosteum and a large venous plexus.
The view that the foramina size is determined by their content is explained by the skull embryology. The skull foramina exist as a consequence of neurovascular structures that pass through them, as the ossification of the skull base occurs around preexisting vessels and cranial nerves. After the $8^{\text {th }}$ week of gestation, the cartilage development begins around the already apparent vessels $[8,24]$ since the veins begin to develop at the early of the $5^{\text {th }}$ week [26]. The cartilaginous ossification of the greater sphenoidal wing begins at the $15^{\text {th }}$ gestational week and until the $22^{\text {nd }}$ week; the FO appears as a large defect in the sphenoidal wing [24]. Finally, the cartilaginous ossification takes place in a fixed pattern from the posterior to anterior axis.

The ESF lies in close proximity to the FO and when appears, transmits an emissary vein connecting the pterygoid venous plexus with the cavernous sinus. Specifically, the ESF location and content forced Wood-Jones [42] to view the ESF as an extension of 
the FO. He concluded that the ESF may either replace the FO venous part, resulting to a smaller FO, or may be confluent with the FO or consist as an additional venous outlet to the FO [42]. Moreover, Schmalfuss and Camp [31] mentioned that the confluence ESF-FO and the transmission of the sphenoidal emissary veins via the FO, in the absence of the ipsilateral ESF is a possible explanation for the FO asymmetry.

The hypothesis tested in this paper, is that the ESF may alter the FO venous part and thus the FO size. After our investigation regarding the FO morphometry, we concluded that the ESF absence or presence (bilateral or unilateral) has no effect on the FO size. Specifically, we detected side symmetry of the FO dimensions (length and width) in the whole sample, in skulls without ESF, in skulls with bilateral present ESF, with a right-sided and a left-sided ESF. Berge and Bergman [4] and Murugan and Saheb [22] found FO side symmetry in the whole sample of their investigation. The values of FO length and width in skulls with bilateral ESF, with a right- and a left-sided ESF were similar with the values of $F O$ length and width in skulls without ESF. Berge and Bergman [4] found no alteration in FO size in skulls with unilateral ESF.

Based on the findings of the current study, we conclude that the occurrence of the sphenoidal emissary vein does not alter the $\mathrm{FO}$ venous component and that this vein is an additional venous pathway. Furthermore, the symmetry presented in all measurements of the FO further enhances the current point of view that the FO venous plexus is a constant trait.

The ESF is inconstant as regards its presence and quite constant regarding its location anteromedial to the FO. The incidence of the ESF and the side of location presents a wide variability among different studies $[6,10,17,18,30,38]$. In the present study, the ESF occurred in $40 \%$ of the skulls ( $21.5 \%$ bilaterally, $18.5 \%$ unilaterally $-7 \%$ on the right and $11 \%$ on the left side), but no statistically significant difference was detected. Variability existed regarding to the bilateral and unilateral appearance and the side of occurrence $[4,12,25,28,30]$. Several proposals highlighted the variability of the ESF presence owing to ethnic differences, evolutionary processes [32] and the fact that the ESF represents the site of fusion between the membrane bone and ala temporalis [15]. Based on the developmental anatomy of the skull foramina and veins, a possible explanation for the ESF variability is that the emissary sphenoidal vein usually follows the venous structures variability.
Another important feature of the present study is the positive correlation between ESF size and the distance FO-ESF. This finding comes in contradiction to the results reported by Ozer and Govsa [25] who found a negative correlation between the ESF perimeter and the distance FO-ESF.

The current study has a limitation: only dry skulls free of pathological process are included. A detailed investigation on cadaveric material taking into account the emissary veins in the area of the greater sphenoidal wings would be useful. Moreover, equally important would be the examination of the greater sphenoidal wing foramina in pathological skulls with abnormal size and shape.

The FO position at the transition zone between intracranial and extracranial structures makes the foramen important to various surgical and diagnostic procedures, such as the percutaneous trigeminal rhizotomy or compression of the Gasserian ganglion for the treatment of trigeminal neuralgia [4], the percutaneous biopsy of parasellar lesions, and the electroencephalographic analysis of the temporal lobe among patients undergoing selective amygdalohippocampectomy for the treatment of epilepsy. The meticulous knowledge of the typical and variable anatomy of the middle cranial fossa is of paramount importance for clinicians during transovale procedures, as the outcome of FO cannulation may be affected by the ESF presence, the confluence FOESF, the existence of osseous spurs [36] and osseous bridging [34] into the FO cranial aperture [40] leading to false entry into the cavernous sinus and the internal carotid artery $[2,3,15]$. Multiple attempts at cannulating the difficult-to-access FO may be associated with vascular complications. Stereotactic approach combined with three-dimensional computed tomographic reconstruction model may improve the accuracy, safety and efficiency of percutaneous radiofrequency thermocoagulation in patients with trigeminal neuralgia [11]. In terms of neurosurgery, although the FO is always possible to reach (by using neuro-navigation) [4], crossing it may be almost impossible due to its narrowness or the presence of osseous spurs or intraforaminal bridges [5].

\section{CONCLUSIONS}

Foramen ovale morphometric details in skulls without ESF, in skulls with bilateral ESF, right and left-sided ESF were investigated. As a result, the ESF absence or presence (bilateral or unilateral) has no 
effect on the FO size. The emissary sphenoidal vein is an additional venous pathway connecting the cavernous sinus with the pterygoid venous plexus. These findings enhance the current opinion that the FO venous plexus is a constant trait, clarifying concurrently a not-well examined topic.

\section{Acknowledgements}

The authors wish to thank all those who donated their bodies and tissues for the advancement of education and research. Authors are also grateful to the donors' families.

\section{REFERENCES}

1. Agarwal DR, Gupta SBA. Morphometeric analysis of foramen ovale and foramen spinosum of human sphenoid bone in the south gujarat population: vital for medical practitioners in cases of trigeminal neuralgia. JARBS. 2012; 4: 243-245.

2. Arrese I, Lobato RD, Alén JF, et al. Acute subdural and intratemporal hematoma as a complication of percutaneous compression of the gasserian ganglion for trigeminal neuralgia. Neurocirugia (Astur). 2005; 16(2): 177-182, indexed in Pubmed: 15915308.

3. Arrese I, Urculo E. Needle insertion in the foramen ovale. Acta Neurochir (Wien). 2011; 153(1): 201; author reply 202, doi: 10.1007/s00701-010-0768-5, indexed in Pubmed: 20811758.

4. Berge JK, Bergman RA. Variations in size and in symmetry of foramina of the human skull. Clin Anat. 2001; 14(6): 406-413, doi: 10.1002/ca.1075, indexed in Pubmed: 11754234.

5. Bohnstedt BN, Tubbs RS, Cohen-Gadol AA. The use of intraoperative navigation for percutaneous procedures at the skull base including a difficult-to-access foramen ovale. Neurosurgery. 2012; 70(2 Suppl Operative): 177-180, doi: 10.1227/NEU.0b013e3182309448, indexed in Pubmed: 21822157.

6. Boyd GI. The emissary foramina of the cranium in man and the anthropoids. J Anat. 1930; 65(Pt 1): 108-121, indexed in Pubmed: 17104299.

7. Daimi SR, Siddiqui AU, Gill SS. Analysis of foramen ovale with special emphasis on pterygoalar bar and pterygoalar foramen. Folia Morphol. 2011; 70(3): 149-153, indexed in Pubmed: 21866524.

8. Di leva A, Bruner E, Haider T, et al. Skull base embryology: a multidisciplinary review. Childs Nerv Syst. 2014; 30(6): 991-1000, doi: 10.1007/s00381-014-2411-x, indexed in Pubmed: 24740442.

9. Dogan NU, Fazliogullari Z, Uysal I, et al. Anatomical examination of the foramens of the middle cranial fossa. Int J Morphol. 2014; 32(1): 43-48, doi: 10.4067/s071795022014000100008.

10. Ginsberg LE, Pruett SW, Chen MY, et al. Skull-base foramina of the middle cranial fossa: reassessment of normal variation with high-resolution CT. AJNR Am J Neuroradiol. 1994; 15(2): 283-291, indexed in Pubmed: 8192074.

11. Guo Z, Wu B, Du C, et al. Stereotactic approach combined with $3 \mathrm{D} C \mathrm{CT}$ reconstruction for difficult-to-access foramen ovale on radiofrequency thermocoagulation of the gasserian ganglion for trigeminal neuralgia. Pain Med. 2016; 17(9): 1704-1716, doi: 10.1093/pm/pnv108, indexed in Pubmed: 26874883.

12. Gupta N, Yadav D, Thomas P, et al. Incidence of Foramen Vesalius in Adult Human North Indian Crania. IOSR J Dental Med Scien. 2014; 13(5): 34-38, doi: 10.9790/085313553438.

13. Hayashi N, Sato H, Tsuboi Y, et al. Consequences of preoperative evaluation of patterns of drainage of the cavernous sinus in patients treated using the anterior transpetrosal approach. Neurol Med Chir (Tokyo). 2010; 50(5): 373-377, indexed in Pubmed: 20505291.

14. Henderson WR. A note on the relationship of the human maxillary nerve to the cavernous sinus and to an emissary sinus passing through the foramen ovale. J Anat. 1966; 100(Pt 4): 905-908, indexed in Pubmed: 5969985.

15. James TM, Presley R, Steel FL. The foramen ovale and sphenoidal angle in man. Anat Embryol (Berl). 1980; 160(1): 93-104, indexed in Pubmed: 7469039.

16. Kaplan M, Erol FS, Ozveren MF, et al. Review of complications due to foramen ovale puncture. J Clin Neurosci. 2007; 14(6): 563-568, doi: 10.1016/j.jocn.2005.11.043, indexed in Pubmed: 17169562.

17. Lang J, Maier R, Schafhauser O. [Postnatal enlargement of the foramina rotundum, ovale et spinosum and their topographical changes]. Anat Anz. 1984; 156(5): 351-387, indexed in Pubmed: 6486466.

18. Lazarus L, Naidoo N, Satyapal KS. An osteometric evaluation of the foramen spinosum and venosum. Int J Morphol. 2015; 33(2): 452-458, doi: 10.4067/s071795022015000200008.

19. Liang $L$, Diao $Y, X u$ Q, et al. Transcranial segment of the trigeminal nerve: macro-/microscopic anatomical study using sheet plastination. Acta Neurochir (Wien). 2014; 156(3): 605-612, doi: 10.1007/s00701-013-1920-9, indexed in Pubmed: 24158246.

20. Lin MHC, Lee MH, Wang TC, et al. Foramen ovale cannulation guided by intra-operative computed tomography with integrated neuronavigation for the treatment of trigeminal neuralgia. Acta Neurochir (Wien). 2011; 153(8): 1593-1599, doi: 10.1007/s00701-011-1009-2, indexed in Pubmed: 21503836.

21. Murlimanju BV, Reddy GR, Latha VP, et al. Foramen of vesalius: prevalence, morphology, embryological basis and clinical implications. J Surg Academia. 2015; 5: 24-28.

22. Murugan M, Saheb S. Morphometric and morphological study on foramen ovale. Int J Anat Res. 2014; 2(4): 664-667, doi: 10.16965/ijar.2014.518.

23. Natsis K, Repousi E, Sofidis G, et al. The osseous structures in the infratemporal fossa: foramen ovale, bony spurs, ossified ligaments and their contribution to the trigeminal neuralgia. Acta Neurochir (Wien). 2015; 157(1): 101-103, doi: 10.1007/s00701-014-2197-3, indexed in Pubmed: 25100153.

24. Nemzek WR, Brodie HA, Hecht ST, et al. MR, CT, and plain film imaging of the developing skull base in fetal specimens. AJNR Am J Neuroradiol. 2000; 21(9): 1699-1706, indexed in Pubmed: 11039353. 
25. Ozer MA, Govsa F. Measurement accuracy of foramen of vesalius for safe percutaneous techniques using computerassisted three-dimensional landmarks. Surg Radiol Anat. 2014; 36(2): 147-154, doi: 10.1007/s00276-013-1148-7, indexed in Pubmed: 23793788.

26. Padget $\mathrm{DH}$. The development of the cranial venous system in man, from the viewpoint of comparative anatomy. Contrib Embryol. 1957; 36: 79-140.

27. Patil J, Kumar N, Mohandas Rao KG, et al. The foramen ovale morphometry of sphenoid bone in South Indian population. J Clin Diagn Res. 2013; 7(12): 2668-2670, doi: 10.7860/JCDR/2013/7548.3727, indexed in Pubmed: 24551606.

28. Raval BB, Singh PR, Rajguru J. A morphologic and morphometric study of foramen vesalius in dry adult human skulls of gujarat region. J Clin Diagn Res. 2015; 9(2): AC04AC07, doi: 10.7860/JCDR/2015/11632.5553, indexed in Pubmed: 25859437.

29. Ray B, Gupta N, Ghose S. Anatomic variations of foramen ovale. Kathmandu Univ Med J (KUMJ). 2005; 3(1): 64-68, indexed in Pubmed: 16401947.

30. Rossi AC, Freire AR, Prado FB, et al. Morphological characteristics of foramen of Vesalius and its relationship with clinical implications. J Morphol Scien. 2010; 27: 26-29.

31. Schmalfuss IM, Camp M. Skull base: pseudolesion or true lesion? Eur Radiol. 2008; 18(6): 1232-1243, doi: 10.1007/ s00330-008-0882-4, indexed in Pubmed: 18270709.

32. Sharma NA, Garud RS. Morphometric evaluation and a report on the aberrations of the foramina in the intermediate region of the human cranial base: A study of an Indian population. Eur J Anat. 2011; 15: 140-149.

33. Shinohara AL, de Souza Melo CG, Silveira EM, et al. Incidence, morphology and morphometry of the foramen of Vesalius: complementary study for a safer planning and execution of the trigeminal rhizotomy technique. Surg Radiol Anat. 2010; 32(2): 159-164, doi: 10.1007/s00276009-0562-3, indexed in Pubmed: 19760356.

34. Skrzat J, Walocha J, Srodek R. An anatomical study of the pterygoalar bar and the pterygoalar foramen. Folia Mor- phol. 2005; 64(2): 92-96, indexed in Pubmed: 16121326.

35. Skrzat J, Walocha J, Srodek R, et al. An atypical position of the foramen ovale. Folia Morphol. 2006; 65(4): 396-399, indexed in Pubmed: 17171622.

36. Skrzat J, Walocha J, Zawiliński J. Accessory spine of the foramen ovale. Folia Morphol. 2012; 71(4): 263-266, indexed in Pubmed: 23197146.

37. Somesh MS, Sridevi HB, Prabhu LV, et al. A morphometric study of foramen ovale. Turk Neurosurg. 2011; 21(3): 378-383, doi: 10.5137/1019-5149.JTN.3927-10.2, indexed in Pubmed: 21845575.

38. Srimani P, Mukherjee P, Sarkar M, et al. Foramina in alisphenoid. Observational study on their osseomorphology and morphometry. Int J Anat Radiol Surg. 2014; 3: 1-6.

39. Standring S. he Anatomical Basis of Clinical Practice. In Gray's Anatomy, 41 th Edition. Elsevier Churchill Livingstone, London 2015.

40. Tubbs RS, Dixon J, Loukas M, et al. Regional vascular relationships to the foramen ovale: an anatomical study with application to approaches to the external skull base with an emphasis on transcutaneous procedures for the treatment of trigeminal neuralgia. J Neurosurg. 2010; 113(3): 493-497, doi: 10.3171/2010.3.JNS091454, indexed in Pubmed: 20302392.

41. Williams LS, Schmalfuss IM, Sistrom $C L$, et al. $M R$ imaging of the trigeminal ganglion, nerve, and the perineural vascular plexus: normal appearance and variants with correlation to cadaver specimens. AJNR Am J Neuroradiol. 2003; 24(7): 1317-1323, indexed in Pubmed: 12917119.

42. Wood-Jones F. The Non-metrical Morphological Characters of the Skull as Criteria for Racial Diagnosis: Part I: General Discussion of the Morphological Characters Employed in Racial Diagnosis. J Anat. 1931; 65(Pt 2): 179-195, indexed in Pubmed: 17104312.

43. Yanagi S. [Developmental studies on the foramen rotundum, foramen ovale and foramen spinosum of the human sphenoid bone]. Hokkaido Igaku Zasshi. 1987; 62(3): 485-496, indexed in Pubmed: 3610040. 